
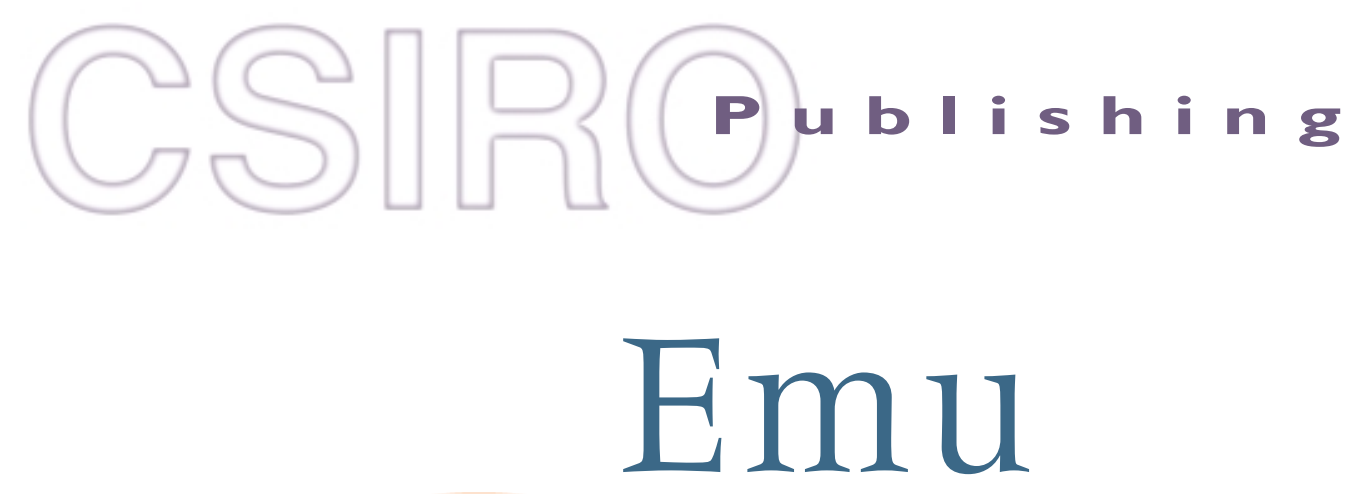

Volume 101, 2001

(C) Birds Australia 2001

All enquiries and manuscripts should be directed to:

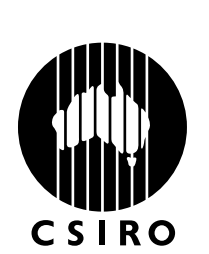

Emu

CSIRO Publishing

PO Box 1139 (150 Oxford St)

Collingwood, Vic. 3066, Australia

PUBLISHING Telephone: +61 396627622

Fax: +61 396627611

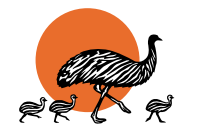

Email: emu@publish.csiro.au

Published by CSIRO Publishing

Birds Australia for the Royal Australasian Ornithologists Union

www.publish.csiro.au/journals/emu 


\title{
Population estimates of Yellow-eyed Penguins, Megadyptes antipodes, on Campbell Island, 1987-98
}

\author{
Peter J. Moore ${ }^{\mathrm{A}}$, David Fletcher ${ }^{\mathrm{B}}$ and Jacinda Amey ${ }^{\mathrm{C}}$

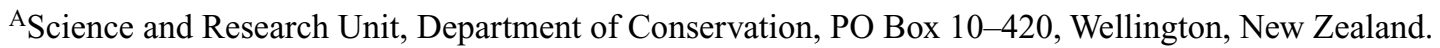 \\ Email: pmoore@doc.govt.nz \\ ${ }^{B}$ Mathematics and Statistics, University of Otago, PO Box 56, Dunedin, New Zealand. \\ ${ }^{C}$ Southland Conservancy, Department of Conservation, PO Box 743, Invercargill, New Zealand.
}

\begin{abstract}
A census of Yellow-eyed Penguin, Megadyptes antipodes, landing sites on Campbell Island in the New Zealand subantarctic in winter 1992 recorded 1034 birds. From mark-recapture analysis of banded birds at one site, the total population was estimated at $1347 \pm 91$ birds, a decrease of $41 \%$ since 1988 , when there were $2277 \pm 122$ birds. The main population centres, in decreasing order of abundance, were at Perseverance Harbour, Northeast Harbour, Northwest Bay and Southeast Harbour. In 1992, 140 landing sites were found, 32 fewer sites than in 1988, although a new area with 14 birds was found on the Col coast. Counts at 11 landing sites were used as an index for population change from 1987 to 1998. These showed that penguin numbers decreased between 1988 and 1992, stayed low until 1994 and then began to increase again. Population trends differed in degree and timing at the three bays of Northwest Bay and at Southeast Harbour and, by 1998, total counts at the former area were still only $50 \%$ of that found in 1988 , whereas at the latter they were $41 \%$ higher.
\end{abstract}

\section{Introduction}

The Yellow-eyed Penguin, Megadyptes antipodes, or hoiho, is one of the rarest species of penguin and breeds in the New Zealand region on the south-eastern coastline of the South Island, Stewart Island and its outliers, and on the subantarctic Auckland and Campbell Islands (Turbott 1990; Moore 1992a) (Fig. 1). Penguins nest in scattered aggregations under the cover of coastal forest and scrub, and hence their numbers are difficult to assess (Darby 1989). In small study areas, breeding pairs are found by laborious searches of coastal vegetation. At other sites, pairs are estimated by comparing counts of birds travelling to and from the sea during the incubation and guard stages of the breeding season (Darby 1985, 1989). Yellow-eyed Penguins enter and exit the sea at sheltered bays and harbours, generally at sandy or small boulder beaches but also at rock platforms (Moore $1992 a$ ). They generally go to sea at dawn and return in the evenings using the same landing site; however, on longer trips, particularly during incubation, birds can stay at sea for up to 7 days (Seddon 1988; Moore 1999).

In 1985/86 there were an estimated 1544-2130 breeding pairs of Yellow-eyed Penguins (New Zealand Wildlife Service 1986). On the basis of Richdale's (1957) calculation that $60 \%$ of the population were breeders, the overall population was estimated at 5146-7100 birds (New Zealand Wildlife Service 1986). Poor seasons (Darby and Seddon 1990; van Heezik and Davis 1990) and a population crash in 1989/90 (Gill and Darby 1993) resulted in a sharp decrease in numbers on the South Island. Over the next 6 years, the number of breeders recovered to pre-crash levels (Efford and Spencer 1996)

Campbell Island is a Nature Reserve, $660 \mathrm{~km}$ south of New Zealand's South Island at 52 $33^{\prime} \mathrm{S}, 169^{\circ} 09^{\prime} \mathrm{E}$. The island is volcanic in origin and shaped by glaciation and erosion by the sea. Much of the coastline is cliff. The woody shrubs Dracophyllum longifolium and D. scoparium clothe the sheltered harbours, and the remaining vegetation is dominated by tussock grassland and herbfields (Department of Lands and Survey 1983; Department of Conservation 1997).

Yellow-eyed Penguins were first reported on Campbell Island in 1840 (Gray 1844) and in 1874 they were 'fairly numerous' (Filhol 1885). In the 1940s, the main breeding areas were Perseverance Harbour, Southeast Harbour, Northeast Harbour, Rocky Bay, Northwest Bay (Bailey and Sorensen 1962), and Monument Harbour (J. Sorensen, unpublished diaries, 1942-47, Department of Conservation Library, Wellington) (Fig. 1). Westerskov (1960) considered that Perseverance Harbour was the principal area, followed by Northwest Bay, and thought it unlikely that the population of Campbell Island would exceed 200 pairs. Although this figure was not derived from a census, it was the only estimate available for the island (e.g. New Zealand Wildlife Service 1986).

A census on Campbell Island in 1988 estimated that there were 1625-2000 Yellow-eyed Penguins (c. 490-600 breeding pairs) and identified the island as a major stronghold for 


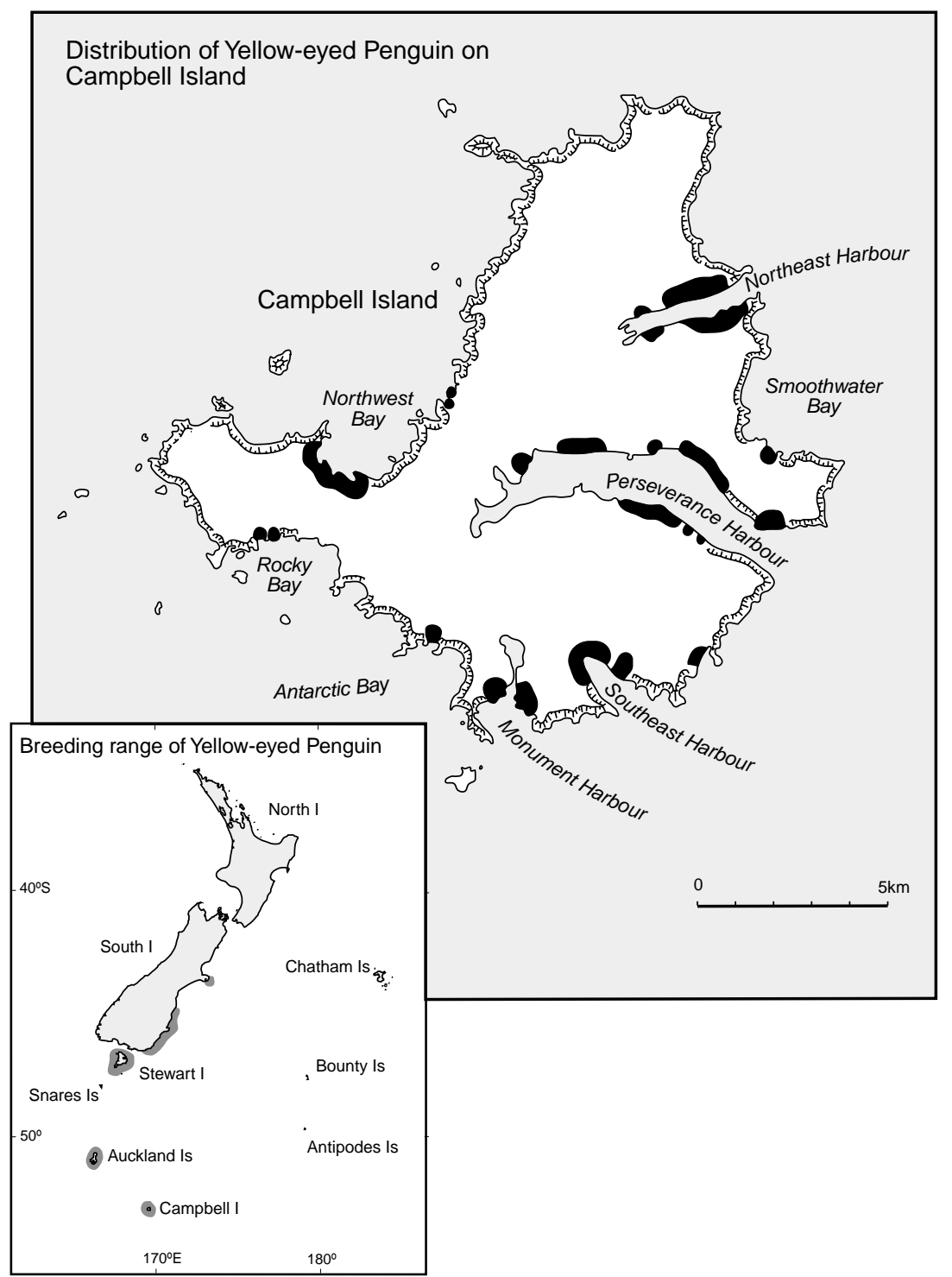

Fig. 1. Distribution of Yellow-eyed Penguins on Campbell Island, based on landing sites found in 1988 and 1992. Steep and inaccessible coastline is shown.

the species (Moore 1992a). Most (79\%) birds were found in four bays (Moore 1992a; Fig. 1), and 172 landing sites on shingle/small-boulder beaches $(61 \%)$ and rocky shores (39\%) were identified. Moore and Moffat (1990) established a series of index-counting sites for the purpose of lowintensity monitoring of the population. The present paper updates the Campbell Island population analysis (Moore $1992 a$ ) to document population trends over a 12-year period.

\section{Methods}

The pattern of movements by Yellow-eyed Penguins at their landing sites was established by conducting two whole-day counts each month from November 1991 to February 1993 following methods used in 1987/88 (Moore 1992a). Counts were conducted at Sandy Bay landing site NW2 (Fig. 2) and were usually shared between two observers taking 4-h shifts. Vantage points near the landing site were chosen so that band numbers could be read using binoculars or telescope while not disturbing the birds. Birds were counted from before dawn till after dusk, usually on two consecutive days: 12 November; 11, 31 December 1991; 13, 14 January; 12, 13 February; 12, 13 March; 12, 13 April; 12, 13 May; 11, 12 June; 11, 12 July; 12, 13 August; 12, 13 September; 12, 13 October; 12, 13 November; 12, 13 December 1992; 11, 12 January; and 12 February 1993. Arrival and departure times (NZ Standard Time) of arrival and departure were recorded for each bird or group.

At Sandy Bay in October-November 1991, 72 birds were banded (with stainless steel flipper bands) at 36 nests. Band recoveries in 1991/92 were made by reading penguin band numbers at nests in the study area and during monthly beach counts.

The 1992 census followed methods used in 1988 (Moore and Moffat 1990; Moore 1992a). All sections of accessible coastline were 
checked for landing sites by looking for birds landing, footprints in mud or snow, tracks heading inland or birds heard calling in the scrub. Counts of all known and new landing sites on the island were carried out between May and August. Each count of a site, or group of sites (if they could be viewed from one vantage point), was for $2.5-3 \mathrm{~h}$ in the morning (starting before dawn) or evening (finishing after dusk), covering the times of peak departures or arrivals, respectively. Most counts were conducted from vantage points above the shoreline, except in Perseverance Harbour, where a small boat was used as a vantage point, and at Northeast Harbour, where many landing sites were counted from kayaks.

A total population estimate was based on the number and identity of banded birds compared with total numbers counted during beach counts at the study areas (Appendix 1). Mark-recapture analysis was employed because not every bird travelled to sea every day and the proportion changed during the months of the census. Derivation of the standard error and confidence limits for the population estimate are given in Appendix 2.

Counts were conducted at eight landing sites in Northwest Bay (site numbers NW2, 3, 7, 8, 10, 11, 12 and 13: Fig. 2) and three in Southeast Harbour (sites SE5, 11 and 12: Fig. 3) as an index for population monitoring. During 1987/88 and 1991-95, index counts were conducted four times per year in November, February, May and August. Counts covered the peak times of departures or arrivals and, depending on the time of year (and daylight hours) or stage of the breeding season, the counts lasted 2.5-3 h (e.g. most morning counts, especially in May) to $8 \mathrm{~h}$ (e.g. afternoon counts in February). The amount of effort required to cover the peak of departures and arrivals depended on the daylight hours and was determined from the whole-day counts at Sandy Bay. The 11 index sites and a few others were also counted on an opportunistic basis in other years between 1987 and 1998, mostly in November. Most (75\%) counts in the data series were single counts but some were counted 2-5 times on consecutive days.

Neighbouring landing sites tended to have opposite trends of population change, therefore they were grouped before statistical analysis by their location within the same bay: Sandy Bay (NW2-3); Middle Bay (NW7-8); Capstan Cove (NW10-13) and Southeast Harbour (SE5-12). The mean count for a bay (2-4 landing sites) was taken to be the sum of the mean counts for the individual sites. The data

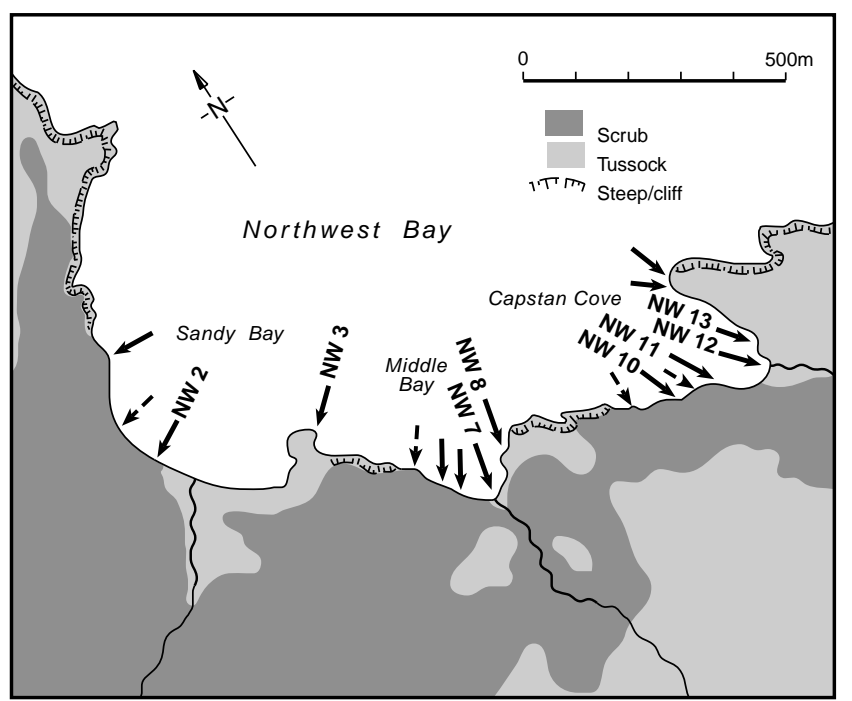

Fig. 2. Location of Yellow-eyed Penguin landing sites at Northwest Bay and those used for index counts. Minor sites (1-2 birds) in 1988 and 1992 are shown as dashed arrows. were log-transformed before analysis, as this led to the assumption of constant error variance being more closely satisfied. A three-factor linear model was used to provide an initial overall analysis. The factors were bay, year (linear, quadratic and cubic effects) and month (the four times of year: centred around November, February, May and August). The purpose of the quadratic and cubic effects was to provide a flexible degree of non-linearity in the trends.

In order to check for any possible serial correlation in the errors for the linear model, we paired each residual with that in the previous year (where applicable) for the same group of sites and the same month. The correlation coefficient between these two sets of residuals was -0.30 $(P=0.04)$, implying that the standard errors of the coefficients in the model will be overestimated. As our purpose in the analysis was solely to provide a means of effectively summarising the trends, this underestimation of the precision of the analysis would not appear to be a problem.

\section{Results}

\section{Monthly counts}

The monthly pattern of numbers of Yellow-eyed Penguins counted during beach counts at Sandy Bay is shown in Fig. 4. Each monthly bar represents the average of 4 counts ( 2 sets of departures and arrivals) on 2 days at landing site NW2, except for November 1991 and February 1993, which had only one day of counting. Numbers peaked at a mean of 133 birds in January 1992, decreased to 38 in April, increased to 104 in June before decreasing again to a low of 36 in October 1992. From November 1992 to February 1993, counts were only $39-52 \%$ of those in the previous year.

Up to 30 juveniles (from the 1990/91 breeding season) were seen during the monthly counts at Sandy Bay during the 1991/92 summer. The first moulting juvenile was found on 2 March 1992. Very few (0 or 1$)$ juveniles were seen each month in the summer of 1992/93 (Fig. 4).

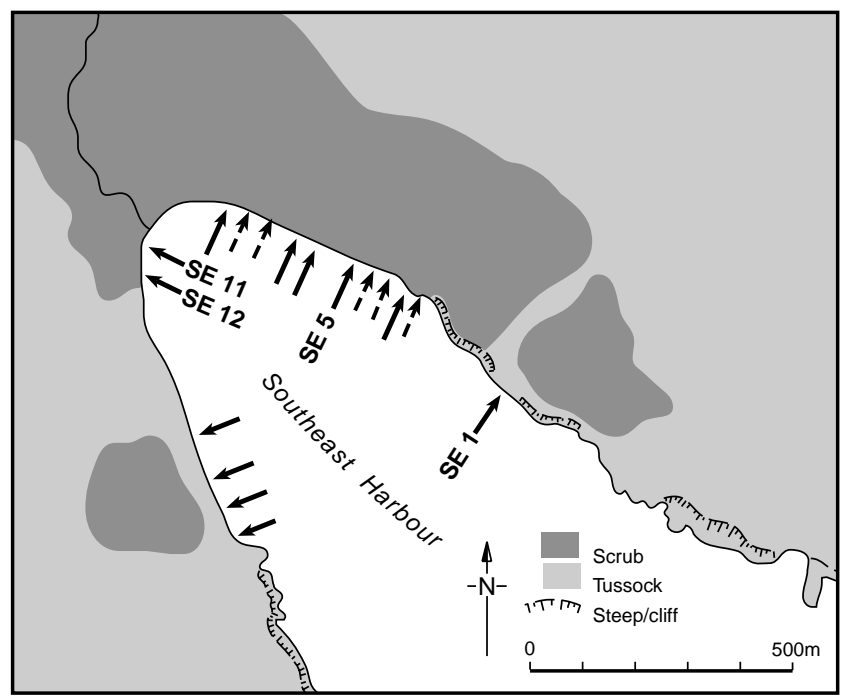

Fig. 3. Location of Yellow-eyed Penguin landing sites at Southeast Harbour and those used for index counts or occasional counts (SE1). Minor sites (1-2 birds) in 1988 and 1992 are shown as dashed arrows. 


\section{Banded adults}

Most banded birds were faithful to the main landing sites at Middle Bay and Sandy Bay, although a few birds used immediately adjacent sites as alternative routes ashore, especially during disturbance by Hooker's Sea Lion, Phocarctos hookeri. Sandy Bay, in particular, was prone to disturbance by sea lions, which congregated there.

Band recoveries were less frequent after the end of the breeding season in March as birds were seen during beach counts only, rather than at nests. Bands on birds were difficult to read during the peak of arrivals and departures because of low light levels and their habit of gathering in groups of 10-50 birds. Consequently, only 12-56 (1988) and 20-37 (1992) bands were read each month from April to September. Some individuals were not seen for up to 4 months (mean $1.3 \pm 0.6, n=98$ gaps in the record) in $1987 / 88$ before they

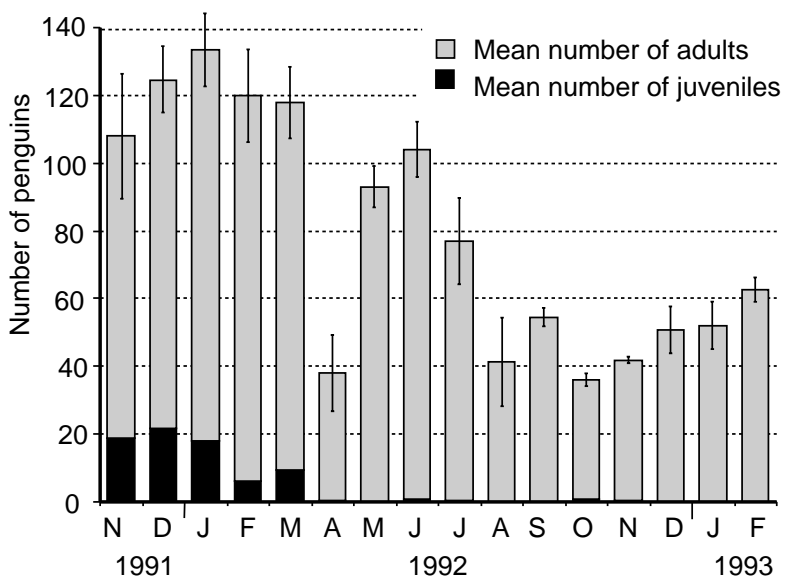

Fig. 4. Mean monthly counts of Yellow-eyed Penguins at NW2, Sandy Bay, 1991-93. Numbers of juveniles are at the base of the bar and adults are the main bar, \pm 1 SD of total ( $n=4$ counts). were re-sighted. Mark-recapture analysis (Appendix 1) suggested that $8(10 \%)$ of the original 78 banded birds had disappeared by July 1988 . Although mortality was known to be high in July, it cannot be estimated from band data as there were only two further consecutive months of beach counts. Because band sightings were more difficult at Sandy Bay, some individuals were not re-sighted for 8 months (mean $2.0 \pm 1.7, n=109$ gaps in the record) in 1991-93 before they were re-sighted. Mark-recapture analysis suggests that, of the original 72 banded in November/December, 32 (44\%) had disappeared by July 1992. None of these banded birds were found nesting during the next breeding season, nor were they seen during beach counts in subsequent years. Of the 34 birds from 1991/92 still known to be present in 1992/93, only 23 were found breeding.

\section{Census}

In total, 1034 individual Yellow-eyed Penguins, including 32 juveniles, were counted in winter 1992 at 140 landing sites (Table 1, Fig. 1). The penguins at the four main areas of Northwest Bay, Northeast, Perseverance and Southeast Harbours comprised $83 \%$ of the total. A new area with 14 birds was found on the Col coast.

Total population estimates were made from the census results based on mark-recapture analysis of banded birds and proportions of banded birds in beach counts at Middle Bay and Sandy Bay (Appendix 1). This gave totals for the whole island of $2277 \pm 122$ penguins in 1988 and $1347 \pm 91$ in 1992 (Appendix 1), a decrease of $41 \%$.

\section{Index counts}

Index counts at 11 sites are summarised in Table 2. Over the 12-year period, numbers decreased, stayed low during 1993 and 1994 and then began to increase again. Between 1987/88 and 1991/92 at Northwest Bay decreases were 13-68\% depending on the month (Table 2). By February 1998, the

Table 1. Numbers and distribution of Yellow-eyed Penguins counted on Campbell Island in May-July 1988 (Moore $1992 a$ ) and May-August 1992

Dashes indicate no count was conducted in 1988

\begin{tabular}{|c|c|c|c|c|c|c|c|}
\hline \multirow[t]{2}{*}{ Locality } & \multicolumn{2}{|c|}{1988} & \multicolumn{4}{|c|}{1992} & \multirow{2}{*}{$\begin{array}{c}\text { Change } \\
\text { 1988-92 }\end{array}$} \\
\hline & No. of sites & Total & No. of sites & Adult & Juv. & Total & \\
\hline Northwest Bay & 17 & 448 & 13 & 210 & 2 & 212 & $-53 \%$ \\
\hline Northeast Harbour & 68 & 312 & 51 & 226 & 11 & 237 & $-24 \%$ \\
\hline Perseverance Harbour & 54 & 261 & 43 & 236 & 5 & 241 & $-8 \%$ \\
\hline Southeast Harbour & 16 & 260 & 14 & 156 & 6 & 162 & $-38 \%$ \\
\hline Monument Harbour & 6 & 136 & 6 & 65 & 5 & 70 & $-49 \%$ \\
\hline Shag Point & 3 & 121 & 4 & 28 & 2 & 30 & $-75 \%$ \\
\hline Antarctic Bay & 1 & 44 & 2 & 23 & 0 & 23 & $-48 \%$ \\
\hline Smoothwater Bay & 4 & 23 & 2 & 21 & 0 & 21 & $-9 \%$ \\
\hline Rocky Bay & 3 & 20 & 3 & 23 & 1 & 24 & $+20 \%$ \\
\hline Col & - & - & 2 & 14 & 0 & 14 & - \\
\hline Total & 172 & 1625 & 140 & 1002 & 32 & 1034 & $-36 \%$ \\
\hline
\end{tabular}


Table 2. Summary of counts of adult Yellow-eyed Penguins at 8 sites in Northwest Bay and 3 sites at Southeast Harbour, Campbell Island, at four times of the year

Counts were adjusted to core hours when necessary (e.g. for the whole-day counts at NW2 and NW7) for comparability across all years. Means of multiple counts at some sites were used. Dashes indicate that no data were collected

\begin{tabular}{lccccccccccc}
\hline & 1987 & 1988 & 1990 & 1991 & 1992 & 1993 & 1994 & 1995 & 1996 & 1997 & 1998 \\
\hline Northwest Bay & & & & & & & & & & & \\
$\quad$ Nov. & 193 & - & - & 168 & 80.3 & 69 & 105 & 89.3 & 107 & - & - \\
Feb. & - & 347.8 & - & - & 193 & - & 129 & 145 & - & - & 167 \\
$\quad$ May-Jul. & - & 380 & - & - & 160.5 & - & 143.5 & 188 & - & - & - \\
$\quad$ Aug. & - & 240.3 & - & - & 96 & - & 162 & 154 & - & - & - \\
Southeast Harbour & & & & & & & & & & & \\
$\quad$ Nov. & 55 & - & 37 & 59.5 & 38 & 43 & 44 & 61 & 57 & 76 & - \\
Feb. & - & 86 & - & - & 55 & 51 & 67 & 77 & - & - & 121 \\
May & - & 106 & - & - & 66 & - & 77 & 104 & - & - & - \\
Aug. & - & 84 & 52 & - & 69 & - & 82 & 102 & - & - & - \\
\hline
\end{tabular}

total count at the 8 landing sites in Northwest Bay was still approximately half that seen in 1988 (Table 2). At Southeast Harbour, penguin numbers fluctuated, but they were down by 33-38\% in most months of 1990 and 1992 compared with the first set of counts in 1987/88. Numbers soon increased in the mid-1990s, and the February 1998 count was a record high, $41 \%$ higher than counted a decade earlier (Table 2).

A linear model (see Methods) was developed to identify any overall trends in the index counts. After sequentially removing non-significant terms from the model, the interactions bay*year, bay*year ${ }^{2}$, bay*year ${ }^{3}$ and month*year were statistically significant $\left(R^{2}=93 \%, P<0.05\right.$ in all cases). This implied that there were non-linear trends that differed at the four bays and time of year. The trends are summarised in Fig. 5.

The curves and raw data shown in Fig. 5 suggest that counts at Sandy Bay were highest around 1987, started decreasing in 1992, and by 1994 had decreased by about $40 \%$, after which numbers began to increase. At Middle Bay there was a rapid decrease in 1988, and by 1992 the decline was $90 \%$ with no sign of recovery in following years. At Capstan Cove there was a concurrent decrease of about 55\%, and a slow recovery after about 1993 . There was also a 30\% decrease at Southeast Harbour but recovery began as early as 1992 and by 1995 index counts exceeded the numbers seen in 1987 (Fig. 5). For each area, the different months showed a similar shape to their curves, with the exception of February, which lagged behind by several years. This is because the February 1998 results were not as high as would be predicted by extrapolating the curves for the other months.

Daily variation in the number of birds using the landing sites is shown by multiple counts (Table 3 ). At Middle Bay, in 1987/88, the variation during the two whole days of counting in most months of 1987 was within a few birds of the mean (mean $\mathrm{CV}=5.3 \%, n=7$ months, Table 3, where $\mathrm{CV}=$ s.d./mean). In other months, e.g. April and July-September (mean $\mathrm{CV}=23.2 \%, n=4$ ) the variation was higher. At Sandy
Bay in 1991-93, variation of counts was usually moderate (mean $\mathrm{CV}=8.5 \%, n=13$ months) but high in November 1991, April and August 1992 (mean CV $=27.5 \%, n=3$ months). Further tests of variation were made at Sandy Bay landing site NW2 by multiple counts on consecutive days in 1995 and 1996; counts were consistent for each series (mean $\mathrm{CV}=5.4 \%, n=4$, Table 3 ). For all months combined in Table 3, mean CV was $11.1 \%(n=31)$.

In addition to the regular index counts, birds at seven other landing sites in three bays were counted occasionally between 1988 and 1997 (Table 4). Counts in winter 1992 at the outer reaches of Southeast Harbour, Shag Point and Monument Harbour were $23-52 \%$ of the number counted in 1988. The counts in October-November at Southeast Harbour suggest a decrease before 1990 and a gradual increase in the mid-1990s. Counts at Shag Point also increased in 1992-94, but to only $50 \%$ of the 1988 level. In contrast, counts at Monument Harbour remained low between 1992 and 1994 (Table 4).

We tested for the effects of disturbance at the study areas (breeding adults were handled once for banding and measuring in October or November and nests were visited every five days until March, to monitor success, and to weigh chicks in 1987/88 and 1991-93). This was achieved by adding an indicator variable to the linear model used to summarise the trends in the index count data. The variable was given the value of 1 if beach counts coincided with nest visits at Middle Bay or Sandy Bay, and 0 otherwise (outside the breeding season or at other index count sites). This showed no evidence $\left(F_{1,74}=1.18, P=0.28\right)$ that the relevant beach counts at NW2-3 and NW7-8 were different from what they would have been without the visits, nor was there evidence of an effect if an indicator variable was used during the counting period after the nest visits $\left(F_{1,74}=3.62, P=0.06\right)$. It should be noted, however, that the power of these tests is not high. For example, for both tests, there is approximately a $70 \%$ chance of not detecting a $25 \%$ reduction in the count. 

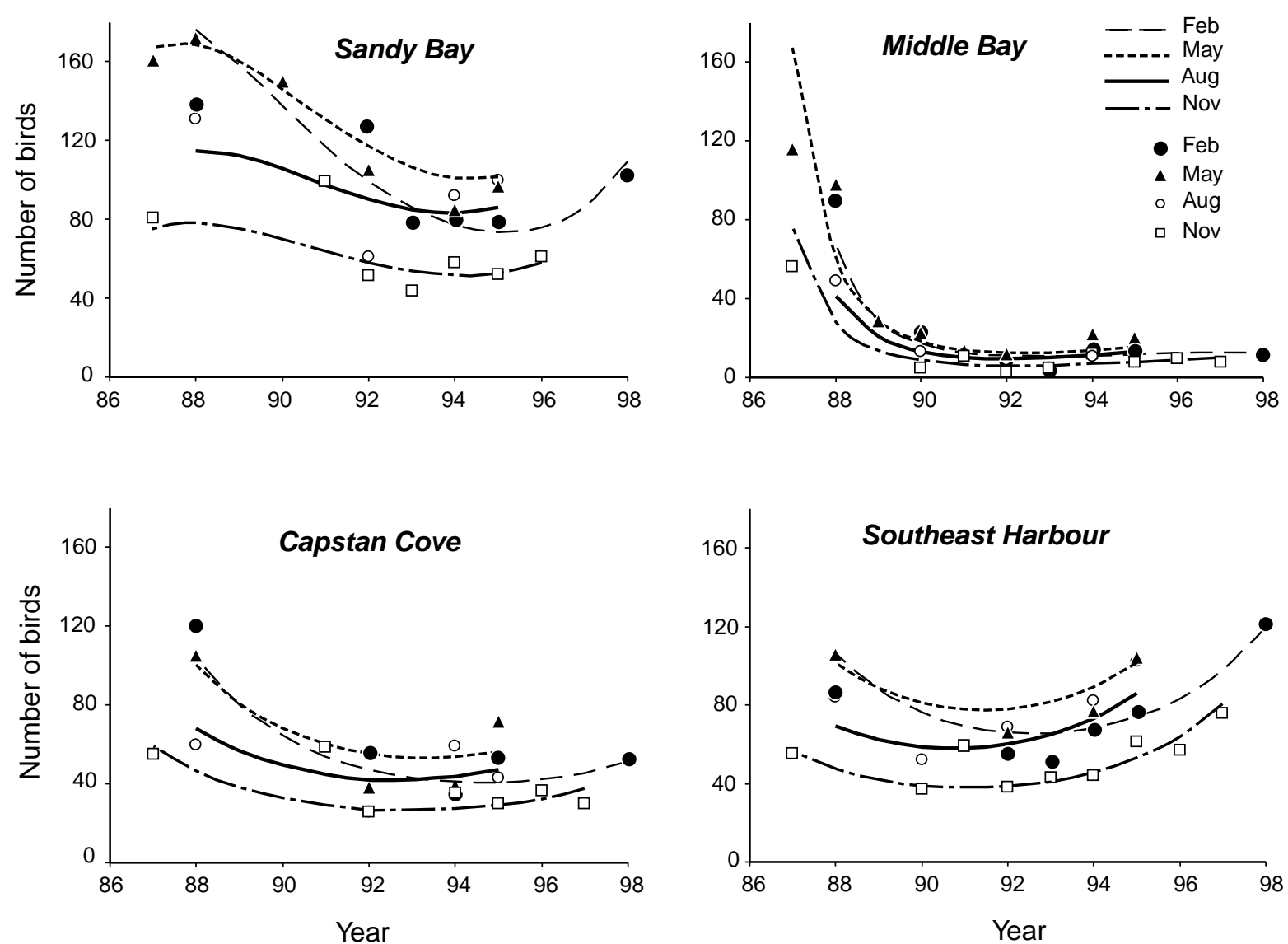

Fig. 5. Index counts of Yellow-eyed Penguins on Campbell Island at four groups of landing sites (Sandy Bay: NW2, NW3; Middle Bay: NW7, NW8; Capstan Cove: NW10, NW11, NW12; Southeast Harbour: SE5, SE11, SE12) from 1987 to 1998. Raw data are shown as points and trend lines have been fitted to the data for each month.

\section{Discussion}

\section{The beach count method}

It has been assumed that beach counts of Yellow-eyed Penguins early in the breeding season relate to the numbers of nests (e.g. Darby 1985, 1989) and hence can be an index to the size of the breeding population. This could not be fully tested with our Campbell Island data as the nest search area at the study sites was smaller than the available breeding habitat, but it appeared a reasonable assumption from the banding data. For example, counts in October/November at Middle Bay (1988) and Sandy Bay $(1991,1992)$ included nearly half $(44.3 \pm 7.6 \%, n=14)$ the number of banded birds (the other half were incubating the eggs and therefore did not travel to sea on the day of the count). The relationship changed each month with the changing pattern of nest duties and foraging-trip duration (e.g. December: $63.7 \pm 21.6 \%$, $n=12$ ). It is recognised, though, that the proportion of birds breeding varies among years (Efford et al. 1994), as does the foraging pattern (Moore 1999).

It is also assumed that beach counts will provide an index of the total population size. In winter on Campbell Island, a high and consistent proportion $(80.4 \pm 10.0 \%, n=20$ counts: May/June 1988 and May-July 1992) of banded birds travelled to sea each day at the study areas, with little daily variation between counts (Table 3). Early winter, therefore, is a good time to assess a population of Yellow-eyed Penguins. The few daylight hours concentrate the departures of penguins in the morning and the arrivals at night into short periods of 2-3 h. Thus, the onerous task of visiting and counting every landing site on the island for censuses becomes more manageable. In contrast, the mid-summer counts are extended, and index counts only are practicable.

Winter counts on the South Island of New Zealand have not been attempted as surveys were done during the breeding season. Monitoring of penguin numbers has centred around intensive nest studies at several coastal Otago sites (Efford et al. 1994), beach counts at other sites in October and December (Darby 1985, 1989) and estimates of numbers at rarely visited sites. However, because there is no standard monitoring protocol, interpretation and syntheses of data are difficult (Efford and Spencer 1996). The Campbell Island work was based on methods used on the South Island, but a 
Table 3. Variation between multiple counts of adult Yellow-eyed Penguins at Middle Bay site NW7 in 1987/88 and Sandy Bay site NW2 in 1991-97

Most counts were of birds moving in or out on two consecutive whole-day counts (i.e. 4 counts) except in 1995-97, when counts were on different days. Note that the means are higher than for Table 3 as data were not reduced to core hours. $\mathrm{CV}=\mathrm{s} . \mathrm{d} . / \mathrm{mean}$.

\begin{tabular}{|c|c|c|c|c|c|c|c|c|c|c|c|c|}
\hline \multirow[t]{2}{*}{ Month } & \multicolumn{3}{|c|}{$1987 / 88$} & \multicolumn{3}{|c|}{$1991 / 92$} & \multicolumn{3}{|c|}{$1992 / 93$} & \multicolumn{3}{|c|}{ 1995-97 } \\
\hline & $\begin{array}{l}\text { Mean } \\
\text { count }\end{array}$ & $\begin{array}{c}\text { CV } \\
\%\end{array}$ & $\mathrm{~N}$ & $\begin{array}{l}\text { Mean } \\
\text { count }\end{array}$ & $\begin{array}{c}\text { CV } \\
\%\end{array}$ & $\mathrm{~N}$ & $\begin{array}{l}\text { Mean } \\
\text { count }\end{array}$ & $\begin{array}{c}\text { CV } \\
\%\end{array}$ & $\mathrm{~N}$ & $\begin{array}{l}\text { Mean } \\
\text { count }\end{array}$ & $\begin{array}{l}\text { CV } \\
\%\end{array}$ & $\mathrm{~N}$ \\
\hline Oct. & - & & - & & & & 35.3 & 4.8 & 4 & 41.6 & 4.0 & 5 \\
\hline Nov. & 52.3 & 4.5 & 4 & 89.0 & 22.2 & 2 & 41.5 & 1.4 & 4 & 33.8 & 5.1 & 4 \\
\hline Dec. & 84.8 & 6.7 & 4 & 102.5 & 6.3 & 4 & 50.8 & 13.7 & 4 & - & & \\
\hline Jan. & 88.5 & 3.0 & 4 & 115.3 & 9.9 & 4 & 51.8 & 13.5 & 4 & 71.0 & 4.0 & 2 \\
\hline Feb. & 94.3 & 6.7 & 4 & 113.5 & 11.3 & 4 & 62.5 & 5.6 & 2 & - & & \\
\hline Mar. & 86.8 & 5.3 & 5 & 108.5 & 8.4 & 4 & - & & & - & & \\
\hline Apr. & 29.8 & 14.4 & 4 & 37.8 & 28.6 & 4 & - & & & - & & \\
\hline May & 95.0 & 2.7 & 4 & 92.8 & 6.6 & 4 & - & & & 62.0 & 8.5 & 3 \\
\hline Jun. & 85.3 & 8.0 & 4 & 103.3 & 7.8 & 4 & - & & & - & & \\
\hline Jul. & 66.0 & 43.5 & 4 & 76.5 & 16.4 & 4 & - & & & - & & \\
\hline Aug. & 44.5 & 20.6 & 4 & 41.3 & 31.6 & 4 & - & & & - & & \\
\hline Sep. & 32.5 & 14.3 & 4 & 54.3 & 5.3 & 4 & - & & & - & & \\
\hline
\end{tabular}

monitoring programme was standardised for the island to allow comparisons between surveys in different years. Whatever time is chosen for a census, it is necessary to calibrate the results at study areas to allow interpretation of counts at other landing sites.

Although only 11 landing sites on Campbell Island were chosen for an index of population change, they included some of the most populous landing sites and in total comprised $22-30 \%$ of the estimated island total in 1988 and 1992. Care is still required in interpreting the trends at individual sites or small groups of sites, particularly when numbers are low, as daily variation may be greater than the annual trend. Because counts were not replicated in some years of less intensive monitoring, one anomalous count caused by an influx of non-breeders, disturbance or bad weather might give spurious results. However, the degree of variation shown in Table 3 is small relative to the trends shown in Fig. 5. Moreover, for each group of sites, there is enough consistency in the trends across months to suggest that the overall patterns were not unduly affected by the day on which each count was made.

On the South Island of New Zealand, daily variation in beach counts has not been fully tested, apart from a series of counts in July-September 1993 and July 1994 (P. Moore and B. McKinlay, unpublished data). During each month, two counts were made on consecutive days. Variation was low in most cases (mean $\mathrm{CV}=6.4 \pm 5.4 \%, n=9$ ) but two other sets of counts in September were highly variable $(\mathrm{CV}=22.5$, 87.5\%). In August 1994, six consecutive counts were conducted at two areas with highly variable results $(\mathrm{CV}=45.5$, 47.9\%) (P. Moore and B. McKinlay, unpublished data). Campbell Island counts were also the most variable in July/August, suggesting that the pre-breeding period is not a reliable period for beach counts.

\section{Seasonal patterns in numbers}

The seasonal pattern of beach counts of Yellow-eyed Penguins at Sandy Bay in 1991/92 was similar to that found at Middle Bay in 1987/88 (Moore 1992a). Numbers of birds counted were generally higher in the chick-rearing months of December-March, low during incubation and the April moult, and high during winter months.

In November, approximately half the number of breeding birds would be counted each day as birds alternated incubation duties with their partners. At least 40 nests were known inland of the landing site (Amey and Moore 1995), so the

Table 4. Counts of Yellow-eyed Penguins at selected landing sites of Southeast Harbour (SE1), Shag Point (SP1, SP2) and Monument Harbour (MH: W1, W2, E2, E4)

\begin{tabular}{lccccccc}
\hline & 1988 & 1990 & 1992 & 1994 & 1995 & 1996 & 1997 \\
\hline SE1 (Oct.-Nov.) & - & 21 & - & 25 & - & 33 & 30 \\
SE1 (May-Jun.) & 74 & - & 29 & 31 & 41 & - & - \\
SP1, SP2 (Nov.) & - & - & - & - & - & 25 & - \\
SP1, SP2 (May-Jul.) & 119 & - & 27 & 59 & - & - & - \\
MH: W1, W2, E2, E4 (May-Jul.) & 121 & - & 63 & 64.5 & - & - & - \\
\hline
\end{tabular}


mean count of 89 adults in November 1991 was very high, suggesting a high non-breeder component on the day of the count. By December 1991, 19 of the 36 study nests had failed and hence counts included further non-breeders. This was during the guard stage, and the remaining successful breeders alternated days at the nest with their partners, and some changed over twice a day. Later, during the post-guard stage (January-March), both partners of breeding pairs were usually at sea each day, and some made more than one trip each day. Hence the peak in numbers at that time.

By March 1992, most juveniles and a number of failed and non-breeders had come ashore to moult. Breeding adults moulted in April and therefore numbers travelling to and from the sea decreased. Counts increased again in winter as most (76\%) birds were feeding at sea each day. However, the winter peak in numbers was proportionally lower than seen in 1987/88 (Moore 1992a) because mortality was higher (44\%) and at an earlier stage of the year. A sharp decrease in numbers was observed from July to October during both periods of study.

\section{Population estimates}

The census of Yellow-eyed Penguins on Campbell Island in 1992 found 1034 birds, and mark-recapture analysis gave a population estimate of $1200-1550$ birds. This might represent $350-460$ breeding pairs if $60 \%$ of birds were breeders (Richdale 1957), or 410-540 pairs if the proportion was $70 \%$ (Efford et al. 1994). Our estimate from mark-recapture analysis of 2050-2550 birds (610-890 pairs) in 1988 is higher than the previous, more conservative, estimate of 1625-2000 birds (490-600 pairs) (Moore 1992a). That estimate used the total count of birds as the minimum, the maximum was calculated using the proportion of known banded birds counted at the study area, and $60 \%$ were assumed to be breeders (Moore 1992a).

Not only was there a $41 \%$ population decrease between 1988 and 1992, but the number of landing sites also decreased by 19\% (Moore 1992a; Table 1). In fact, by comparing field maps, it appeared that 45 landing sites had disappeared and 13 were new. Some of this may have resulted from field parties overlooking sites, assigning sites in different ways (e.g. combining two adjacent tracks) or because birds took different paths ashore. Only one or two birds were counted at $39(67 \%)$ of the 58 sites; most of these were on the featureless coastlines of Perseverance and Northeast Harbours. At higher population levels the minor sites could represent the overflow from neighbouring sites, particularly as young birds without established residency would be more mobile. There were fewer small landing sites noted in 1992 (Fig. 6) but these had little impact on the overall total count of birds. The main changes occurred at the more populous landing sites. For example, only six sites had counts greater than 20 birds during the 1992 census, in contrast to 15 sites in 1988 (Fig. 6). The highest counts per landing site were 143 in 1988 and 98 in 1992, both at Sandy Bay landing site NW2.

\section{Population trends}

The index counts over the 12 years between 1987 and 1998, combined with the two censuses in 1988 and 1992, allowed a more comprehensive interpretation of population trends than if either technique had been used alone. The decrease in population recorded between censuses appears to have occurred at different times and rates at the different localities in the four intervening years. The populations at Middle Bay, Capstan Cove and Southeast Harbour decreased early and that at Sandy Bay decreased at least two years later. Subsequent increases also began at different times. They were earliest at Southeast Harbour (1992-95), where counts exceeded 1987 levels, later at Sandy Bay (1995-98), barely evident at Capstan Cove, and not evident at Middle Bay, 10 years after the initial decreases. The main landing site at Middle Bay showed the most dramatic change, with counts decreasing from 100 birds to fewer than 10 in 1988, and not recovering. Occasional counts at outer Southeast Harbour, Shag Point and Monument Harbour supported the observations that local populations more than halved between 1988 and 1992, but were recovering by 1995 in most areas.

\section{Causes of numerical change}

Much of the observed decreases in population were apparently a result of high mortality; for example, at Sandy Bay, an estimated $44 \%$ of banded birds disappeared over a seven-month period in 1991/92. Further support for a change in abundance, rather than distribution, is inferred by the lack of band returns from other bays (i.e. adults did not take up residence elsewhere). This, despite two island-wide censuses and regular index counts over a 10-year period at other parts of Northwest Bay and Southeast Harbour. In recent years, banded birds observed at sites other than Middle Bay and

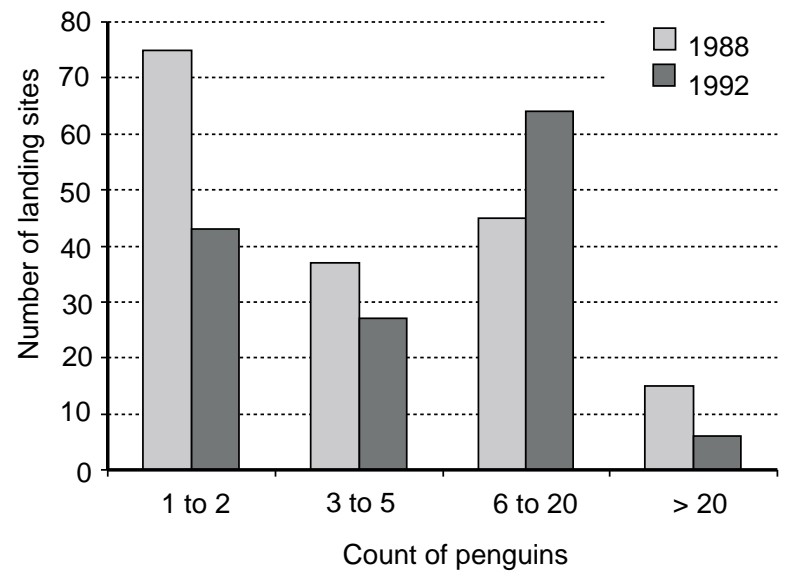

Fig. 6. Number of Yellow-eyed Penguins at landing sites on Campbell Island in 1988 and 1992. 
Sandy Bay were birds that had originally been banded as chicks (P. Moore, unpublished), hence were more likely to disperse than adults. The adult mortality suggested by our results is similar to that recorded for the mainland in 1990 when the population at two intensively monitored sites at Otago Peninsula decreased by $42 \%$ (Efford and Spencer 1996). In other years the population (breeders and non-breeders) varied between decreases of up to $9 \%$ or increases of up to $17 \%$ (Efford and Spencer 1996).

During both periods of more intensive study and monitoring (at Middle Bay in 1987/88 and Sandy Bay in 1991/92) there were major decreases in the penguin population. It is possible that human disturbance during the breeding season influenced these decreases, for example by increasing mortality through stress or by banding the birds. Recent studies have suggested that metal flipper bands on penguins increase drag during swimming, increase mortality and decrease breeding success (Stonehouse 1999) and these effects might be exacerbated in years of low food availability (Culik et al. 1993). In contrast some studies have shown no effect of bands on survival or breeding success (Hindell et al. 1996).

There was no statistical evidence that trends in index counts at disturbed sites on Campbell Island were different from those at undisturbed sites, although the power of these tests was low because of variability in the data. Furthermore, in 1988 breeding success was high (mean production of 1.4 chicks per nest: Moore 1992b) and equivalent to the best seasons on the mainland (Darby and Seddon 1990). Counts at Middle Bay remained high four months after the end of the breeding season in 1988 (Moore 1992a) and the population decrease the following winter was sudden and seemed to be mainly influenced by predatory behaviour of Hooker's Sea Lions (Moore 1992a; Moore and Moffat 1992). There was a small increase in numbers of penguins regularly using the adjacent landing site (NW8) within the same bay but not enough to explain the decrease at NW7. Also, there were decreases in population in bays at which there was no banding or disturbance. Perhaps human disturbance contributed to a poor season at Sandy Bay in 1991/92 as adults and chicks appeared to be stressed during visits to their nests and when handled (J. Amey, unpublished). Success was low ( 0.6 chicks per nest), possibly in part a result of young chicks being handled during bad weather conditions (Amey and Moore 1995); however, the breeding season was also a poor one at other localities (e.g. Catlins 0.9 and Codfish Island 0.5 chicks per nest) (Moore 1999).

It is possible that most of the predation and disturbance at Middle Bay in 1988 was caused by a single Hooker's Sea Lion that had learnt to ambush the penguins in the shallows as they came ashore (Moore and Moffat 1992). Whether the sea lion also preyed on birds at neighbouring Capstan Cove is unknown, but as there was a more widespread decrease between 1988 and 1992 other factors must also have been involved. Penguin corpses from sea lion predation on Campbell Island have been noted in other years, e.g. 1992/93 (Amey and Moore 1995) and 1994/95 (M. Fraser, personal communication). Also, a high number of corpses and skeletons showing signs of predation were seen at a landing site on Enderby Island (Auckland Islands) at different times in 1996-99 (authors' unpublished data; P. McClelland, personal communication). Occasionally, sea lions also take penguins on land (M. Cawthorn, personal communication; J. Amey, unpublished). Another Hooker's Sea Lion showing atypical feeding behaviour killed up to $43 \%$ of the fur seal, Arctocephalus spp., pups on Macquarie Island in one year (Robinson et al. 1999). Clearly, occasional outbreaks of more active predation on penguins by sea lions can have a devastating effect on local populations in the subantarctic. Once populations are depressed in an area, a lack of social activity could fail to attract new recruits and hence numbers remain low for many years.

Decreases in Yellow-eyed Penguin numbers on Campbell Island did not coincide with those on the South Island of New Zealand. The most dramatic recent event occurred in 1989/90 (Gill and Darby 1993), when 40\% adult mortality was recorded, significantly higher than for any other year recorded (Efford et al. 1994; Efford and Spencer 1996). There was an initial quick increase when previous breeders returned after a year off (Efford et al. 1994; Moore et al. 1995), but full recovery of numbers took six years, during which time there was low adult mortality and good recruitment (Efford and Spencer 1996). The Campbell Island mortality event in 1988-92 was similar in extent to the $1989 / 90$ event on the South Island crash, and the first suggestion of a recovery was not until 1994/95 in most areas, with some areas still being $50-90 \%$ down in numbers after a decade. Other areas quickly returned to 1988 levels.

Declines in breeding numbers on mainland New Zealand have been attributed to clearance of coastal forest breeding habitat, predation by introduced mammals, vandalism by people, disturbance by stock, and crashes in the food supply (Richdale 1942; Darby and Seddon 1990; van Heezik 1990; Moore 1999). The cause of the mortality event in $1989 / 90$ is unknown (Gill and Darby 1993) but avian malaria may have been partly responsible (Graczyk et al. 1995).

There are few current land-based problems for Yellow-eyed Penguins on Campbell Island (Moore 1992a). The main human impacts occurred during the whaling, sealing era (1810-1910) and farming eras (1895-1931) when Norway rats, Rattus norvegicus, cats, Felis catus, and sheep, Ovis aries, were introduced, and much of the island was burned to promote pasture grasses (Rudge 1986). Campbell Island was protected as a Nature Reserve in 1954 and was listed, with New Zealand's other subantarctic islands, as a World Heritage Site in 1998. Sheep were progressively removed during 1970-1992 (Rudge 1986) and cats appear to have died out (Moore 1997). Rats are abundant 
(Taylor 1986), and although they were thought to have injured two penguin chicks and possibly killed or scavenged another in 1991/92 (Amey and Moore 1995), there was no evidence of this in 1988 (Moore and Moffat 1990; Moore $1992 b$ ). The effect of disease is unknown; avian malaria is present in the population (Graczyk et al. 1995) and most birds carry ticks (Moore and Moffat 1990), which could transmit viruses and blood parasites. The main threats to survival and breeding success appear to be marine predators, such as sea lions (Moore and Moffat 1992), and perturbations of the food supply (van Heezik 1990; Moore and Wakelin 1997).

Island-wide population changes are most likely a result of perturbations in the food supply that are caused by environmental fluctuations, as occurs off the South Island (van Heezik 1990; Moore 1999). Yellow-eyed Penguins feed over the continental shelf and dive to the sea floor to feed mainly on small fish (Moore and Wakelin 1997; Moore 1999). At Campbell Island they dive up to $160 \mathrm{~m}$ (P. Moore, unpublished), which corresponds to a $10-\mathrm{km}$ foraging range from the island (Cullen 1971). It is not known to what extent changes in sea temperature may have affected the food supply for Yellow-eyed Penguins. Warming of the sea was implicated in the $90 \%$ decline in numbers of Rockhopper Penguins, Eudyptes chrysocome, between the 1940s and 1980s (Cunningham and Moors 1994), which continues to the present (P. Moore, unpublished). There is no suggestion of a similar long-term decline for the Yellow-eyed Penguin population. Rockhopper Penguins feed in deeper water, which is possibly more likely to be affected by changes to oceanic currents than the inshore areas.

\section{Conclusion}

Census data of Yellow-eyed Penguins on Campbell Island from 1988 and 1992, and index counts from 1987 to 1998, provide a baseline from which to interpret any future counts. Most parts of the island shared a decrease in population by more than half between 1988 and 1992 but began recovering by 1995 . Sea lions contributed at least locally to the decrease in numbers in 1988. The poor breeding season in 1991/92, the subsequent high mortality of juveniles and adults during 1992 and deferred breeding in 1992/93, all suggest a problem in the food supply. The changes are probably small parts of long-term fluctuations in population size.

\section{Acknowledgments}

Many people helped us or conducted penguin counts, and thus experienced the hardship of keeping warm in not always very pleasant conditions. Especial thanks to Roger Moffat (1987-88, 1990-91) and Gus McAllister (1991-93) for the help and company during the census work, index counts and monthly study-area counts. We also thank staff of the Meteorological Station (Paul Hadfield, Bill Perry: 1989-91), Ron Goudswaard and Andy Cox (1990) for occasional counts, part-time Department of Conservation staff stationed on the island (Jim Henderson: 1993/94; Gary Mitchell: 1994/95), and volunteers/wage workers (Matt Charteris, Brent Evans, Sheryl Hamilton, Sonja Heinrich, Nathan McNally, Nadine Parker and Alan Wiltshire) for helping or conducting index counts in other years (1996-98). Murray Williams, Hugh Robertson and two anonymous referees commented on drafts of this paper.

\section{References}

Amey, J., and Moore, P. (1995). Yellow-eyed Penguin on Campbell Island. Department of Conservation, Invercargill.

Bailey, A. M., and Sorensen, H. (1962). Subantarctic Campbell Island. Denver Museum of Natural History Proceedings No. 10.

Culik, B. M., Wilson, R. P., and Bannasch, R. (1993). Flipper-bands on penguins: what is the cost of a life-long commitment? Marine Ecology Progress Series 98, 209-214.

Cullen, D. J. (1971). Campbell Island, provisional bathymetry. New Zealand Oceanographic Institute Chart Series 1: 200,000.

Cunningham, D. M., and Moors, P. J. (1994). The decline of rockhopper penguins Eudyptes chrysocome at Campbell Island, Southern Ocean and the influence of rising sea temperatures. Ети 94, 27-36.

Darby, J. T. (1985). The great Yellow-eyed Penguin count. Forest and Bird 16(2), 16-18.

Darby, J. T. (1989). Seabird monitoring in New Zealand. In 'Proceedings of a Symposium on Environmental Monitoring in New Zealand'. (Ed. B. Craig.) pp. 235-239. (Department of Conservation: Wellington.)

Darby, J. T., and Seddon, P. J. (1990). Breeding biology of Yellow-eyed Penguins (Megadyptes antipodes). In 'Penguin Biology'. (Eds L. S. Davis and J. T. Darby.) pp. 45-62. (Academic Press: Orlando, Florida.)

Department of Lands and Survey (1983). Management Plan for the Campbell Islands Nature Reserve. Management Plan Series NR 13.

Department of Conservation (1997). Subantarctic Islands Heritage. Nomination of the New Zealand Subantarctic Islands by the Government of New Zealand for inclusion in the World Heritage List. Department of Conservation, Wellington.

Efford, M., and Spencer, N. (1996). Population studies of Yellow-eyed Penguins. Landcare Research Contract Report LC9697/014, prepared for Department of Conservation.

Efford, M., Darby, J., and Spencer, N. (1994). Population studies of Yellow-eyed Penguins. Landcare Research Contract Report LC9495/39, prepared for Department of Conservation.

Filhol, H. (1885). Oiseaux. In 'Mission de l'Ile Campbell, Passage de Venus sur le Soleil'. Tome III, Ile Partie, pp. 35-64. (Academie des Sciences: Paris.)

Gill, J. M., and Darby, J. T. (1993). Deaths in Yellow-eyed Penguins (Megadyptes antipodes) on the Otago Peninsula during the summer of 1990. New Zealand Veterinary Journal 41, 39-42.

Graczyk, T. K., Cockrem, J. F., Cranfield, M. R., Darby, J. T., and Moore, P. (1995). Avian malaria seroprevalence in wild New Zealand penguins. Parasite 2, 401-405.

Gray, G. R. (1844). Birds of New Zealand. In 'The Zoology of the Voyage of H.M.S. Erebus and Terror, under the command of Captain Sir James Clark Ross, R.N., F.R.S., during the years 1839 to 1843. Vol. 1. Mammalia, Birds'. (Eds J. Richardson and J. E. Gray.) pp. 1-20. (London.)

Hindell, M. A., Lea, M.-A., and Hull, C. L. (1996). The effects of flipper bands on adult survival rate and reproduction in the Royal Penguin, Eudyptes schlegeli. Ibis 138, 557-559. 
Moore, P. J. (1992a). Population estimates of Yellow-eyed Penguin (Megadyptes antipodes) on Campbell and Auckland Islands 1987-90. Notornis 39, 1-15.

Moore, P. J. (1992b). Breeding biology of the Yellow-eyed Penguin Megadyptes antipodes on Campbell Island. Ети 92, 157-162.

Moore, P. J. (1997). Cats on Campbell Island - rare or extinct? Rare Bits (New Zealand Department of Conservation Newsletter) 25, 40.

Moore, P. J. (1999). Foraging range of the Yellow-eyed Penguin Megadyptes antipodes. Marine Ornithology 27, 49-58.

Moore, P. J., and Moffat, R. D. (1990). Yellow-eyed Penguin on Campbell Island. Science and Research Internal Report No. 58, Department of Conservation, Wellington.

Moore, P. J., and Moffat, R. D. (1992). Predation of Yellow-eyed Penguin by Hooker's sealion. Notornis 39, 68-69.

Moore, P. J., and Wakelin, M. D. (1997). Diet of the Yellow-eyed Penguin Megadyptes antipodes, South Island, New Zealand, 1991-1993. Marine Ornithology 25, 17-29.

Moore, P. J., Wakelin, M., Douglas, M. E., Mckinlay, B., Nelson, D., and Murphy, B. (1995). Yellow-eyed Penguin foraging study, South-eastern New Zealand, 1991-1993. Science \& Research Series No. 83, Department of Conservation, Wellington.

New Zealand Wildlife Service (1986). Yellow-eyed Penguin Megadyptes antipodes. Draft Species Recovery Plan. Department of Internal Affairs, Dunedin.

Richdale, L. E. (1942). A comprehensive history of the behaviour of the Yellow-eyed Penguin (Megadyptes antipodes) Homb and Jacqu. Unpublished documents MS 1260/70/1,2. Hocken Library, Dunedin.

Richdale, L. E. (1957). 'A Population Study of Penguins.' (Clarendon Press: Oxford.)

Robinson, S., Wynen, L., and Goldsworthy, S. D. (1999). Predation by a Hooker's sea lion (Phocarctos hookeri) on a small population of fur seals (Arctocephalus spp.) at Macquarie Island. Marine Mammal Science 15, 888-893.
Rudge, M. R. (1986). The decline and increase of feral sheep (Ovis aries L.) on Campbell Island. New Zealand Journal of Ecology $\mathbf{9}$, 89-100.

Seddon, P. J. (1988). Patterns of behaviour and nest site selection in the Yellow-eyed Penguin (Megadyptes antipodes). Ph.D. Thesis, University of Otago, Dunedin.

Stonehouse, B. (1999). Penguin banding: time for reappraisal? Marine Ornithology 27, 115-118.

Taylor, G. A. (1986). The ecology of Norway rats on Campbell Island, Vol. 1,2. Unpublished reports, Ecology Division, Department of Scientific and Industrial Research, Nelson.

Turbott, E. G. (convenor) (1990). 'Checklist of the Birds of New Zealand.' (Random Century \& OSNZ.)

Van Heezik, Y. (1990). Seasonal, geographical, and age-related variations in the diet of the Yellow-eyed Penguin (Megadyptes antipodes). New Zealand Journal of Zoology 17, 201-212.

Van Heezik, Y., and Davis, L. (1990). Effects of food variability on growth rates, fledging sizes and reproductive success in the Yellow-eyed Penguin Megadyptes antipodes. Ibis 132, 354-365.

Westerskov, K. (1960). Birds of Campbell Island. Wildlife Publication No. 61. New Zealand Department of Internal Affairs.

White, G. C., and Burnham, K. P. (1997). Program MARK: Survival Estimation from Populations of Marked Animals. (http://www.cnr.colostate.edu/ gwhite/mark.)

Manuscript received 25 July 2000; accepted 28 November 2000 
Appendix 1. Estimates of population size on Campbell Island using census results, beach-count data at Middle Bay in 1988 and Sandy Bay in 1992 and a mark-recapture model for banded birds

Data are separated by month to allow for the spread of census results over 3-4 months and the possibility of different capture rates.

\begin{tabular}{|c|c|c|c|c|c|c|c|c|c|}
\hline & \multicolumn{4}{|c|}{1988} & \multicolumn{5}{|c|}{1992} \\
\hline & May & Jun. & Jul. & Total & May & Jun. & Jul. & Aug. & Total \\
\hline $\mathrm{N}$ & 1364 & 428 & 485 & 2277 & 429 & 297 & 486 & 134 & 1347 \\
\hline $\operatorname{SE}(N)$ & 98 & 39 & 59 & 122 & 65 & 30 & 53 & 17 & 91 \\
\hline $\mathrm{CV}(\%)$ & 7 & 9 & 12 & 5 & 15 & 10 & 11 & 13 & 7 \\
\hline Lower limit & 1181 & 356 & 380 & 2047 & 318 & 242 & 391 & 104 & 1177 \\
\hline Upper limit & 1576 & 514 & 619 & 2534 & 579 & 364 & 605 & 173 & 1541 \\
\hline$n_{\mathrm{c}}$ & 965 & 332 & 328 & 1625 & 350 & 225 & 386 & 73 & 1034 \\
\hline$p_{\mathrm{c}}(\%)$ & 71 & 78 & 68 & & 82 & 76 & 79 & 54 & \\
\hline $\operatorname{SE}\left(p_{c}\right)(\%)$ & 5 & 7 & 8 & & 12 & 7 & 9 & 5 & \\
\hline$m_{\mathrm{b}}$ & 51 & 55 & 48 & & 43 & 42 & 32 & 16 & \\
\hline $\mathrm{k}$ & 6 & 4 & 4 & & 4 & 4 & 4 & 4 & \\
\hline$N_{\mathrm{b}}$ & 71 & 71 & 70 & & 53 & 55 & 40 & 29 & \\
\hline $\operatorname{SE}\left(N_{\mathrm{b}}\right)$ & 4 & 6 & 8 & & 8 & 5 & 4 & 2 & \\
\hline$N_{\mathrm{k}}$ & 23 & 23 & 23 & & 26 & 26 & 26 & 26 & \\
\hline$N_{\mathrm{e}}$ & 48 & 48 & 47 & & 27 & 29 & 14 & 3 & \\
\hline $\mathrm{n}$ & 39 & 34 & 28 & & 11 & 19 & 8 & 2 & \\
\hline$p(\%)$ & 81 & 71 & 59 & & 41 & 65 & 56 & 59 & \\
\hline $\operatorname{SE}(p)$ & 5 & 6 & 7 & & 7 & 7 & 9 & 8 & \\
\hline
\end{tabular}

Explanation

An estimate of the total population size $(N)$ counted during each month of the census was made as follows. The census count $\left(n_{\mathrm{c}}\right)$ was divided by an estimate of the probability that a bird was counted $\left(p_{\mathrm{c}}\right): \quad N=n_{\mathrm{c}} / p_{\mathrm{c}}$.

The probability $p_{\mathrm{c}}$ was estimated as the mean number of banded birds counted (number of counts $=\mathrm{k}$ ) at the study area $\left(m_{\mathrm{b}}\right)$ divided by the estimated number of banded birds alive $\left(N_{\mathrm{b}}\right): \quad p_{\mathrm{c}}=m_{\mathrm{b}} / N_{\mathrm{b}}$.

The number of banded birds alive was estimated as the sum of those known to be alive $\left(N_{\mathrm{k}}\right)$ from the total originally banded (78 in 1988,72 in 1992), either because they were identified during each month of the census (May-July 1988) or after the census (September 1992), and the estimated number alive amongst the remainder $\left(N_{\mathrm{e}}\right): N_{\mathrm{b}}=N_{\mathrm{k}}+N_{\mathrm{e}}$.

The value of $N_{\mathrm{e}}$ was obtained via a mark-recapture analysis, using the program MARK (White and Burnham 1997). This analysis involved the capture histories for all banded birds, made every month during the periods October 1987 to September 1988 (1988 analysis, Middle Bay) and November 1991 to February 1993 (1992 analysis, Sandy Bay). The histories were grouped according to whether the bird was known to be alive at the end of the sampling period or not. The model fitted assumed a different capture probability for each month, but that these probabilities were the same for the two groups of birds. The monthly survival rates for the birds known to be alive at the end of the sampling period were all set to 1.0 , while those for the remaining birds were estimated. $N_{\mathrm{e}}$ was then calculated as the number of birds caught that month from amongst those not known to be alive at the end of the sampling period $(n)$, divided by the estimated capture rate $(p)$ for that month: $N_{\mathrm{e}}=n / p$.

Derivation of the standard error (SE) and confidence limits for $N$ is given in Appendix 2.

\section{Appendix 2. Derivation of the standard error and confidence limits for $N$, the population size of Yellow-eyed Penguins on Campbell Island}

In deriving the standard error for $N$, it is convenient to make use of the coefficient of variation, $\mathrm{CV}=\mathrm{SE} /$ Estimate. The CV for a ratio of two independent variables $X$ and $Y$, is approximately $\mathrm{CV}(X / Y)=\sqrt{ }\left[\mathrm{CV}(X)^{2}+\mathrm{CV}(Y)^{2}\right]$.

This gives $\mathrm{CV}(N)=\sqrt{ }\left[\mathrm{CV}\left(n_{\mathrm{c}}\right)^{2}+\mathrm{CV}\left(p_{\mathrm{c}}\right)^{2}\right]$,

where $n_{\mathrm{c}}$ has a binomial distribution with parameters $N$ and $p_{\mathrm{c}}$, i.e. $\operatorname{SE}\left(n_{\mathrm{c}}\right)=\sqrt{ }\left[\mathrm{N} p_{\mathrm{c}}\left(1-p_{\mathrm{c}}\right)\right]$

Since $p_{\mathrm{c}}$ is also a ratio of two independent variables, we have $\operatorname{CV}\left(p_{\mathrm{c}}\right)=\sqrt{ }\left[\mathrm{CV}\left(m_{\mathrm{b}}\right)^{2}+\mathrm{CV}\left(N_{\mathrm{b}}\right)^{2}\right]$.

Now $m_{\mathrm{b}}$ is the mean of $\mathrm{k}$ counts, each count having a binomial distribution with parameters $N_{\mathrm{b}}$ and $p_{\mathrm{c}}$, and so $\operatorname{SE}\left(m_{\mathrm{b}}\right)=\sqrt{ }\left[N_{\mathrm{b}} p_{\mathrm{c}}\left(1-p_{\mathrm{c}}\right) / \mathrm{k}\right]$

Since $N_{\mathrm{b}}=N_{\mathrm{k}}+N_{\mathrm{e}}$, and $N_{\mathrm{k}}$ is known, we have $\mathrm{SE}\left(N_{\mathrm{b}}\right)=\mathrm{SE}\left(N_{\mathrm{e}}\right)$.

Now $N_{\mathrm{e}}$ is a ratio of two variables, albeit not independent. However, we get a conservative estimate of its standard error using the same formula above, i.e. $\operatorname{CV}\left(N_{\mathrm{e}}\right)=\sqrt{ }\left[\mathrm{CV}(n)^{2}+\mathrm{CV}(p)^{2}\right]$.

Since $n$ has a binomial distribution with parameters $N_{\mathrm{e}}$ and $p$, we have $\operatorname{SE}(n)=\sqrt{ }\left[N_{\mathrm{e}} p(1-p)\right]$.

Finally, the value for $\mathrm{CV}(p)$ comes from the mark-recapture analysis described in Appendix 1.

Confidence limits for $N$ were calculated by assuming that $\ln N$ has a normal distribution, and using the result that $\operatorname{SE}(\ln N)=\sqrt{ }\left[\ln \left\{1+\mathrm{CV}(N)^{2}\right\}\right]$. 